\title{
Speech Language Therapy
}

National Cancer Institute

\section{Source}

National Cancer Institute. Speech Language Therapy. NCI Thesaurus. Code $C 159273$.

The treatment of communication disorders (speech disorders and language disorders), cognitive-communication disorders, voice disorders, and swallowing disorders. 